\title{
Study on the Reactive Sintering SiC Materials
}

\author{
Hua Xu \& An Xu \\ School of Business, Jingdezhen Ceramic Institute, China
}

\begin{abstract}
SiC ceramic is a new ceramic material. For its excellent performance, it is widely used in the field of mechanical seal. It is used in the pump, blender and other equipment during the petrochemical, aerospace and other industries. In order to further improve the sealing properties of SiC ceramics, this paper study on the $\mathrm{SiC}$ ceramic material preparation of various process parameters influence on its main mechanical properties. During the study, we were investigated in the binder, Si powder size, the effect of carbon density and molding pressure influence on the properties of sintering $\mathrm{SiC}$ ceramic material. We find the optimum route finally.
\end{abstract}

KEYWORD: Sintering SiC ceramic material; Process parameters; Performance

\section{BACKGROUND}

$\mathrm{SiC}$ ceramics is a new ceramic material which developed in recent decades. Due to its special excellent high strength, high hardness, corrosion resistance, high temperature resistance, it has been large-scale development and application. It has been widely used in petroleum, chemical, metallurgy, machinery, aerospace, microelectronics, automotive, steel and other industries of machinery sealing areas. It shows advantages of unmatched by other special ceramics increasingly (Chen Yixin ET AL, 2015). Because the pump, mixer and other equipment working conditions are generally poor, such as high temperature, high pressure, corrosion, wear and so on. There are very high requirements on the performance of sealing materials (Zhang Wei ET AL, 2015). In order to further improve the performance of ceramic sealing material, which is more consistent with the requirements of sealing material. It need to depth study the relationship of preparation process, structure and properties. This paper studies the effect of parameters on the sintering of $\mathrm{SiC}$ ceramic material microstructure and mechanical properties. It gets the best preparation process finally.

\section{EXPERIMENTAL MATERIALS AND EXPERIMENTAL PROCEDURES}

This paper intends to use Sintering $\mathrm{SiC}$ ceramic technology. The main raw materials are $\mathrm{SiC}$ powder, binder, carbon black, Si particles and so on. The $\mathrm{SiC}$ powder is selected particle diameter of $7 \mathrm{~m}, 28 \mathrm{~m}$ and $56 \mathrm{~m}$ the three raw powders. Binder selected the polyvinyl alcohol and phenol resin. Si particle is diameters $5 \sim 8 \mathrm{~mm}$ particles.

The development of the process is shown in Figure 1.

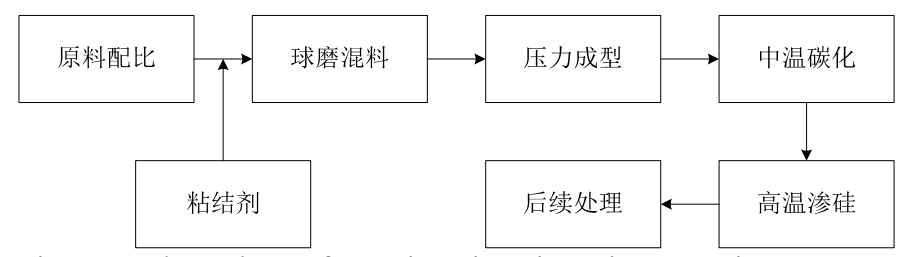

Figure 1 Flow chart of reactive sintering SiC ceramics

We can see from Figure 1, the sintering process of $\mathrm{SiC}$ ceramic has the following process:

(1). The ratio of raw materials: select three different particle sizes of $\mathrm{SiC}$ powder, using two kinds of polyvinyl alcohol and two kinds of binder phenolformaldehydes. Design several corresponding biscuit formula, and determine raw materials, solvents, binder, curing agent and lubricant formulation proportion.

(2). Mixing: using the wet mixing process, in accordance with the formula in the proportion of weighing the raw materials, solvents, adhesives, curing agent and lubricant, and using grinding ball mill.

(3). Blank shaping: weigh a certain amount of the mixture with the mold and press molding, low temperature drying in an oven after molding. 
(4)Temperature carbonization: $\mathrm{SiC}$ biscuit carbonization in the moderate tube oven which protected by argon, carbonized in 800 degree for 2 hours. It ensures that the organic matter is fully cracked.

(5). Permeability and the high temperature ceramic Si: SiC prime billet after the middle temperature carbonization furnace for melting infiltration sintering in the vacuum graphite tube. The Si particles are filled in the BN coated surface of the graphite crucible. Ceramic biscuit is placed above in the Si particles, and together with graphite in the crucible and graphite carbon tube furnace for melting infiltration sintering.

(6). Subsequent processing: Diamond millstone will be attached for removal of the sintering sample surface adhesion of $\mathrm{Si}$, and the sample grinding to reduce the surface roughness and improving surface quality.

\section{SAMPLE CHARACTERIZATION METHOD}

In order to evaluate the mechanical properties of the sample, the samples were measured following methods.

(1). Bending strength

According to the testing method of bending strength of GB/T4741-1999 ceramic materials, flexural strength test of sintering $\mathrm{SiC}$ ceramics samples. The principle is shown in Figure 2.

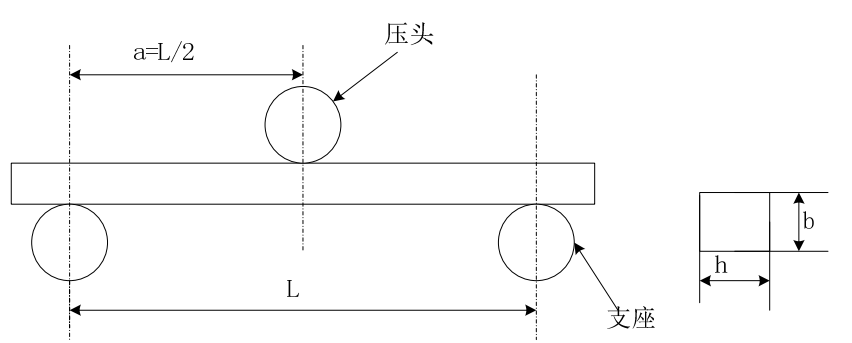

Figure 2 Bending strength test principle diagram

The bending strength calculation formula is as follows:

$\sigma=\frac{\varepsilon P L}{2 b h^{2}}$

In this formula: $\sigma$--three-point bending strength (MPa)

P--the maximum load of fracture $(\mathrm{N})$

L--span (mm)

b--specimen width $(\mathrm{mm})$

h--specimen height $(\mathrm{mm})$

(2). Rockwell hardness

According to the general hardness of sintering SiC ceramics, selected Rockwell HRA to characterize the reaction sintering of $\mathrm{SiC}$ ceramics hardness.
Rockwell hardness test can be read directly by Rockwell hardness tester.

(3). The microstructure and morphology

Reaction-bonded $\mathrm{SiC}$ ceramics after preparation of metallographic specimens, it need to fine diamond grinding wheel grinding, and then size w2.5 diamond grinding polishing paste. It can use the metallographic microscope and scanning electron microscope (SEM) to observe the microstructure of $\mathrm{SiC}$ ceramics.

\section{RESULTS AND DISCUSSION}

(1). Binder effect on the sintering of $\mathrm{SiC}$ ceramic structure and properties

This paper evaluates the effect of binder by $\mathrm{SiC}$ the flexural strength of the slab level. According to previous research experience, $\mathrm{SiC}$ strength of the biscuit must be bigger than $10 \mathrm{MPa}$ to meet the requirement performance. Through the experiments of fixed binder content, compared with the bending strength of polyvinyl alcohol and two kinds of phenol resin binder preparing biscuit. The results are shown in Table 1.

Table 1 flexural strength of different binder $\mathrm{SiC}$ biscuit

\begin{tabular}{llll}
\hline Binder type & $\begin{array}{l}\text { Content } \\
\text { wt } \%\end{array}$ & $\begin{array}{l}\text { Molding } \\
\text { pressure } \\
\text { Mpa }\end{array}$ & $\begin{array}{l}\text { Molding } \\
\text { pressure } \\
\text { Mpa }\end{array}$ \\
\hline Polyvinyl alcohol & 12 & 120 & 7 \\
Phenol resin & 12 & 120 & 18 \\
\hline
\end{tabular}

Comparison of the data can be found, the bending strength of phenol resin as a binder for preparing $\mathrm{SiC}$ biscuit was better than polyvinyl alcohol. The biscuit strength fully meets the requirements of machining strength.

(2). SiC particle size effect on the reaction sintering $\mathrm{SiC}$ ceramic structure and properties

Experiment selected the three particle sizes of $\mathrm{SiC}$ powder, $\mathrm{W} 7(\mathrm{~d} 50=7 \mathrm{~m}), \mathrm{W} 28(\mathrm{~d} 50=28 \mathrm{~m})$ and $\mathrm{f} 280$ $(\mathrm{d} 50=56 \mathrm{~m})$. It produced different particle size of reaction sintering $\mathrm{SiC}$ ceramic material. Then I analyzed the $\mathrm{SiC}$ effect of particle size on the sintering of $\mathrm{SiC}$ ceramics and observed its microstructure characteristics. The density and bending strength were tested. The results are shown in Figure 3 and Figure 4. 


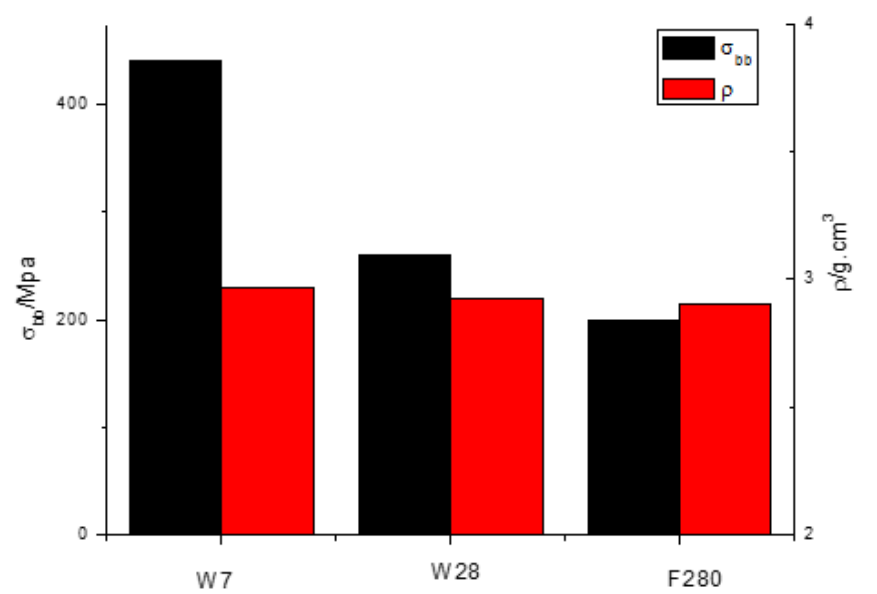

Figure 3 The anti bending strength and density contrast of different particle size of $\mathrm{SiC}$ powder reaction sintering of $\mathrm{SiC}$ ceramics

From Figure 3, we can see that strength flexural strength of reaction bonded $\mathrm{SiC}$ ceramics by $\mathrm{SiC}$ powder particle size effects is very obvious. When the powder particle size increases, the flexural strength of the samples decreased significantly. And sample density pollination particle size has little effect.
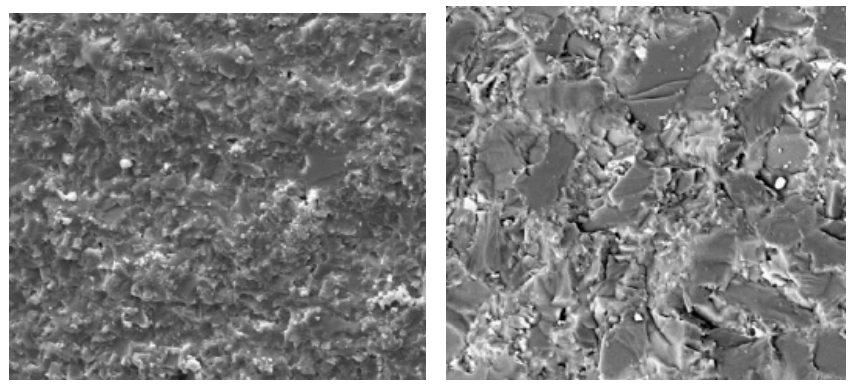

a. W7

b. W28

Figure 4 SEM fracture photograph of reactive sintering $\mathrm{SiC}$

In Figure 4, the fracture is reactive sintering $\mathrm{SiC}$ material's 5000 times magnification pictures. It can be seen from the figure, the reaction sintering of $\mathrm{SiC}$ ceramics failure mainly transgranular fracture, and accompanied by a small percentage of intergranular fracture. When the particle size of $\mathrm{SiC}$ powder is W7, Free Si SiC particle size is small (Figure 4 in white or gray area), and uniform distribution. Because of the strength of $\mathrm{Si}$ is much lower than $\mathrm{SiC}$ ceramics. In the figure $4 \mathrm{~b}$, the local segregation of $\mathrm{Si}$ resulted in coarse particles sintering of $\mathrm{SiC}$ ceramic strength greatly reduced (Zeng Zeng ET AL, 2015).

(3). Effect of carbon density of sintering $\mathrm{SiC}$ ceramics structure and properties.

The study found that the carbon content in the biscuit $\mathrm{SiC}$ effect of the performance of sintering of $\mathrm{SiC}$ ceramic materials. People used to characterize $\mathrm{SiC}$ carbon density carbon content in the biscuit.
According to the definition of carbon density, it is the form of element C's content in SiC compacts per unit volume. We can find that the residual $\mathrm{SiC}$ in the biscuit element $\mathrm{C}$ mainly comes from the mixing when adding carbon black and binder dissociation $\mathrm{C}$. The calculation method is shown as the following formula:

$\rho_{c}=\left(\omega_{c}+\omega_{n} \chi_{c}\right) \rho_{p}$

In this formula: $\rho c$ is carbon density of SiC biscuit. $\omega \mathrm{c}$ and $\omega$ n respectively the biscuit quality percentage of $\mathrm{C}$ and binder. $\chi \mathrm{c}$ is carbon residue cracking rate of carbide binder.

We can adjust the content of black carbon and binder to control the carbon density. Specific formulations are shown in Table 2.

Table 2 Different carbon density SiC biscuit preparation conditions and parameters.

\begin{tabular}{lllll}
\hline Sample & $\begin{array}{l}\text { The content } \\
\text { of carbon } \\
\text { black wt } \%\end{array}$ & $\begin{array}{l}\text { Phenol resin } \\
\text { containing } \\
\text { wt } \%\end{array}$ & $\begin{array}{l}\text { Biscuit } \\
\text { density } \\
\text { g.cm }\end{array}$ & $\begin{array}{l}\text { Carbon den- } \\
\text { sityg.cm }\end{array}$ \\
\hline A1 & 13 & 12 & 1.706 & 0.324 \\
A2 & 18 & 5 & 1.745 & 0.292 \\
A3 & 8 & 8 & 1.723 & 0.186 \\
A4 & 0 & 14 & 1.782 & 0.127 \\
\hline
\end{tabular}

As shown in Figure 5 is the different carbon density of SiC compacts prepared by reaction sintering $\mathrm{SiC}$ material density and hardness.

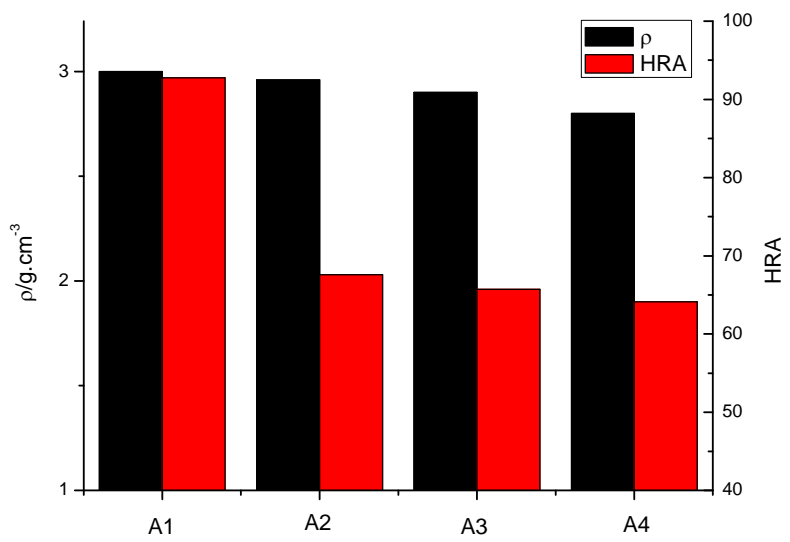

Figure 5 carbon density of biscuit influence on the performance of sintered $\mathrm{SiC}$ ceramics

Comprehensive table 2 and figure 5 , it can be seen that the reduction of carbon density, reaction sintering $\mathrm{SiC}$ material density and hardness decreased. Because the preparation of sintering $\mathrm{SiC}$ materials mainly rely on liquid $\mathrm{Si}$ to $\mathrm{SiC}$ biscuit in the water, and the biscuit $\mathrm{C}$ formation of two SiC. The gap was filled material. It obtained the compact of materials. The higher carbon density decided to generate two times the content of $\mathrm{SiC}$ in the sintering process. Usually carbon density is small, the sintering materials two times the content of $\mathrm{SiC}$ is small, the reac- 
tion sintering SiC material density and hardness decreased (Lu Youjun, 2014).

(4). The effect of molding pressure on the reaction sintering $\mathrm{SiC}$ ceramic structure and properties

Reaction sintering $\mathrm{SiC}$ ceramic material in the sintering process, the biscuit in the permeability is a slow process of liquid phase $\mathrm{Si}$. After the sample was infiltrated density and uniformity of $\mathrm{Si}$ and $\mathrm{SiC}$ biscuit compacting degree of filling, i.e. with a relative density of $\mathrm{SiC}$ biscuit. It means that the relative density of the $\mathrm{SiC}$ pressing pressure depends on the size.

Figure 6 and Figure 7 shows the density of compacts with different molding pressures, the changes of bending strength and hardness.

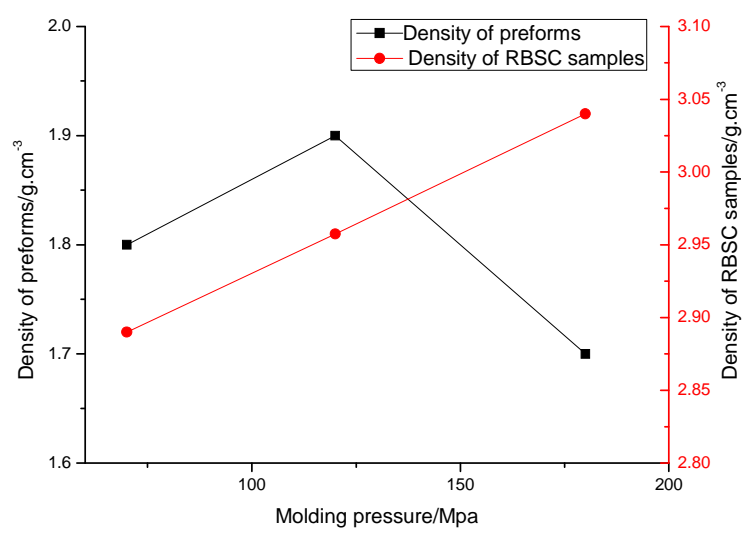

Fig. 6 molding pressure effect on the blank and the density of sintering $\mathrm{SiC}$ ceramics

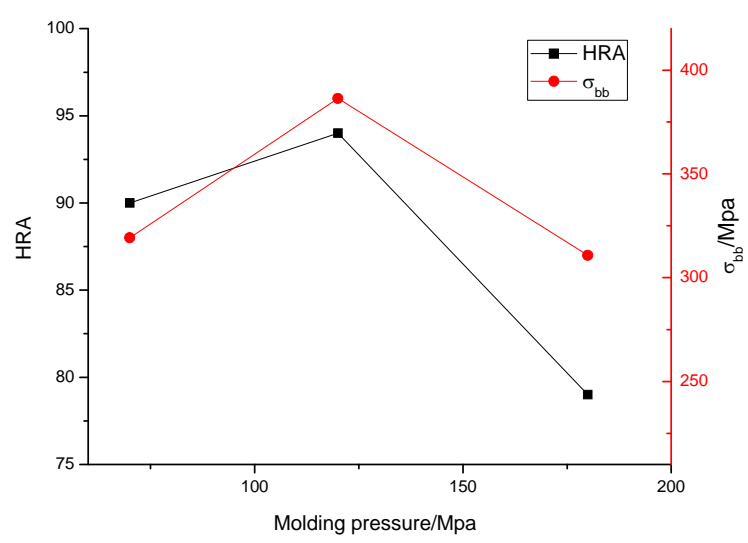

Figure 7 molding pressure influence the bending strength and hardness of sintering $\mathrm{SiC}$ ceramics

From Figure 6 and Figure 7 can be seen, molding pressure of $70 \mathrm{MPa}$ biscuit with low density, pore in the biscuit high and Unicom. It can guarantee the biscuit complete penetration, but after infiltration reaction sintering $\mathrm{SiC}$ ceramic free residual $\mathrm{Si}$ is very high. The mechanical properties of the samples were low. Forming pressure $170 \mathrm{Mpa}$ biscuit density is too high, resulting SiC prime billet for Si liquid penetration into the internal pore closed. Si liquid is difficult to penetrate internal biscuit, leave many pores and carbon residue, density and strength. It also influences the reaction sintering $\mathrm{SiC}$ ceramic material, hardness decreased significantly.

\section{CONCLUSION}

In this paper, through the research on the preparation technique of sintering $\mathrm{SiC}$ ceramic material, obtained the following conclusions: to use the average particle size of $7 \mathrm{um} \mathrm{SiC} \mathrm{powder,} \mathrm{add} 12 \%$ phenol resin as a binder, add $13 \%$ black carbon, and use of $120 \mathrm{Mpa}$ pressure molding biscuit has the best mechanical properties after sintering. Study on Preparation Technology for sintering $\mathrm{SiC}$ ceramic material not only has a great guiding significance to improve the performance of sintering $\mathrm{SiC}$ ceramics, also has certain reference value for the performance optimization of other ceramic materials. The improvement of sintering of $\mathrm{SiC}$ ceramics performance to has a significant role in promoting the development of aerospace and petroleum chemical industry.

\section{REFERENCES}

Chen Yixin, Wang Richu, Wang Xiaofeng. Research progress of porous SiC ceramics [J]. The Chinese Journal of Nonferrous Metals, 2015, 25(8):2146-2156.

$\mathrm{Lu}$ Youjun. Study on the synthesis and properties of carbon nano particle modified silicon carbide ceramic matrix composites [D]. South China University of Technology, 2014.

Wang Dongpo. The processing mechanism of $\mathrm{C} / \mathrm{SiC}$ composite material and processing research [D]. Harbin Institute of Technology, 2013.

Zeng Zeng, Zhang Qingmao. One way $\mathrm{C} / \mathrm{SiC}$ matrix ceramic composites failure mechanism and strength prediction $[\mathrm{J}]$. Acta Materiae Compositae Sinica, 2015, 32(4):1075-1082.

Zhang Wei, Man WEidong, Lin Xiaoqi. Silicon carbide ceramic sealing material on the deposition of diamond composite film [J]. Journal of Synthetic Crystals, 2015(04). 